\title{
Extended temporalis flap for skull base reconstruction
}

\author{
Soon Won Chung, \\ Jong Won Hong, \\ Won Jai Lee, \\ Yong Oock Kim \\ Department of Plastic and \\ Reconstructive Surgery, Institute for \\ Human Tissue Restoration, Yonsei \\ University College of Medicine, Seoul, \\ Korea
}

\begin{abstract}
Traditionally, a galeal flap has been used for skull base reconstruction. In addition to the galeal flap, several other flaps, such as the temporalis muscle flap or the free vascularized flap, can be options for skull base reconstruction, and each option has advantages and disadvantages. Certain cases, however, can be challengeable in the application of these flaps. We successfully managed to cover a skull base defect using an extended temporalis flap. Herein, we present the case and introduce this novel method.
\end{abstract}

Keywords: Reconstructive surgery / Surgical flaps / Temporal artery

\section{INTRODUCTION}

Generally, tumors of the anterior skull base can be challenging because they require consideration of aesthetic result and avoidance of major complications, such as cerebrospinal fluid leakage and meningitis [1]. In anterior skull base reconstruction, two factors must be considered. First, the operation includes the obliteration of the paranasal sinus, coverage of the dura, and blocking cerebrospinal fluid leakage [2]. Second, characteristics of defect should be considered, such as a location, depth and size of defect. According to these factors, reconstructive procedures including skin graft, local flap, and free vascularized flap could be chosen [3-6].

Traditionally, a galeal flap has been used for skull base reconstruction. In some cases involving a defect of the skull base and the cribriform plate, a reverse temporalis muscle flap was used $[7,8]$. The superficial temporal artery should have been included in the temporalis muscle flap instead of the scalp flap when the reverse temporalis muscle flap was elevated [9].

\section{Correspondence: Jong Won Hong}

Department of Plastic and Reconstructive Surgery, Institute for Human Tissue

Restoration, Yonsei University College of Medicine, 50 Yonsei-ro, Seodaemun-gu,

Seoul 03722, Korea

E-mail: saturn@yuhs.ac

Received October 19, 2018 / Revised January 8, 2019 / Accepted February 7, 2019
However, in this case, the brain tumor recurred and invaded the above soft tissue and galea. Due to the invasion of the galea, the forehead galea could not be used. Moreover, after neurosurgery, the scalp flap was already elevated including the superficial temporal artery and vein. Therefore, the reverse temporalis muscle flap was not able to be used. The patient underwent skull base reconstruction using the temporalis muscle flap with deep temporal vessels instead of the superficial temporal vessels. The temporalis muscle flap could not be advanced to the center of the frontal sinus. Therefore, an extended temporalis flap, including the parietal galeal flap, was elevated for skull base reconstruction.

\section{CASE REPORT}

A 50-year-old male suffered from a recurrent brain tumor which had invaded the galeal flap and soft tissue of the forehead (Fig. 1). He initially presented with a seizure when he was 40 years old. A frontal mucocele with abscessus was noted on computed tomography, and the lesion was resected at that time. Nine years later, the tumor recurred in the same area. Because the tumor was larger than its initial presentation, a wide excision and anterior skull base reconstruction were needed. Due to tumor location and invasion, the forehead galea was damaged 


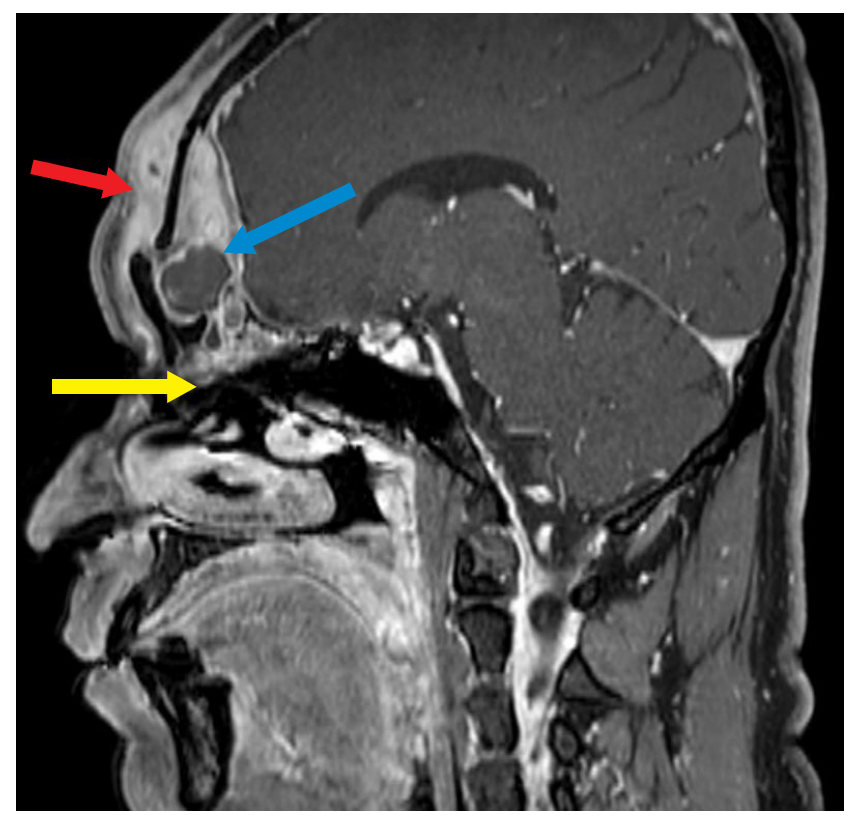

Fig. 1. Preoperative computed tomography of the tumor. The tumor invaded the frontal sinus and soft tissue, including the galeal layer and the nasal cavity on sagittal view (red arrow, invasion of galeal layer; blue arrow, invasion of frontal sinus; and yellow arrow, invasion of nasal cavity).

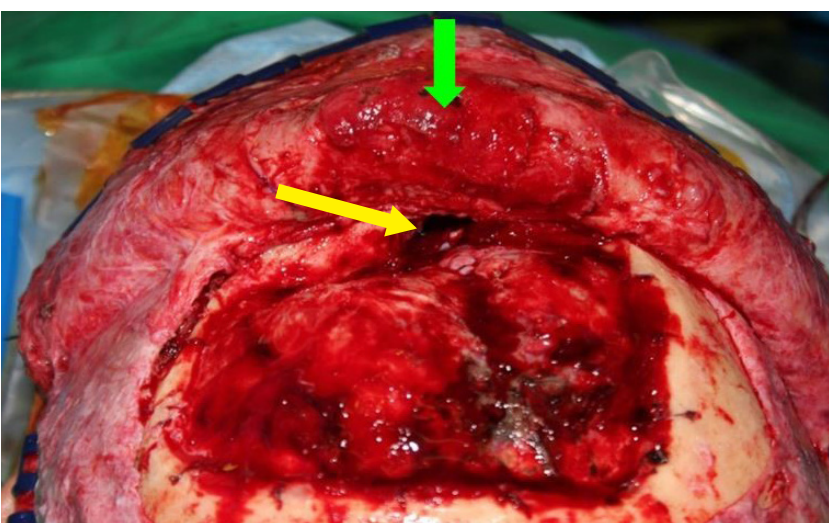

Fig. 2. Intraoperative photograph after resection of tumor. Communication between the cranial cavity and the nasal cavity was noted (yellow arrow). The damaged galeal flap was also noted after removal of the tumor (green arrow).

after tumor removal, so a galeal flap above the lesion could not be used. After removal of the tumor by the neurosurgery team, a communication between the cranial cavity and the nasal cavity occurred, with a $3 \times 3-\mathrm{cm}$-sized skull base defect (Fig. 2).

In order to cover the skull base defect, the neurosurgical team considered multiple reconstructive options. The galeal flap above the frontal sinus was one option, but it had been removed when the tumor was resected. The length of the temporalis muscle flap was too short to reach to the center of the defect. Therefore, an extended temporalis muscle flap was chosen in-

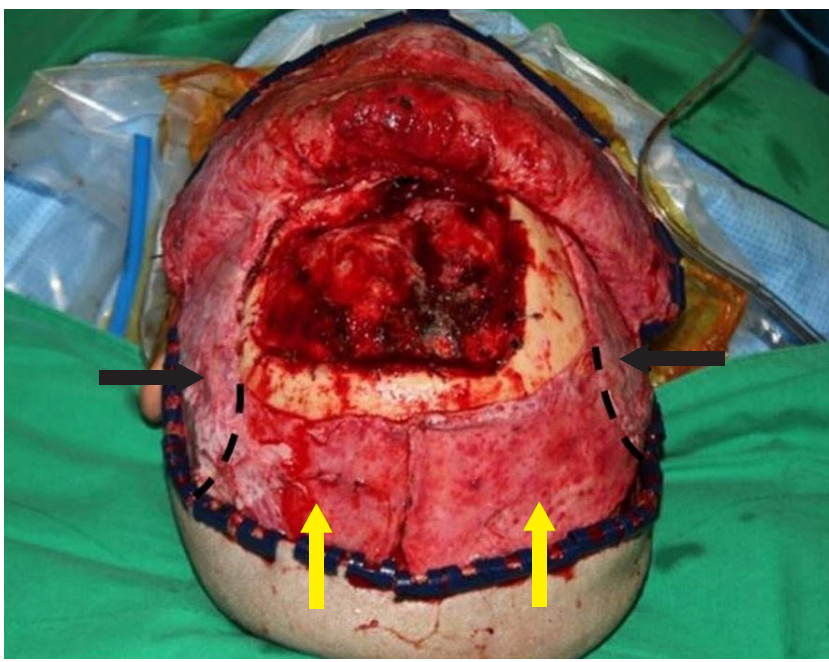

Fig. 3. The extended temporalis muscle flap, consisting of temporalis muscle flap and parietal galeal flap, was elevated (black arrows, temporalis muscle flap; yellow arrows, galeal flap; dotted lines, a border between the temporlis muscle flap and galeal flap).

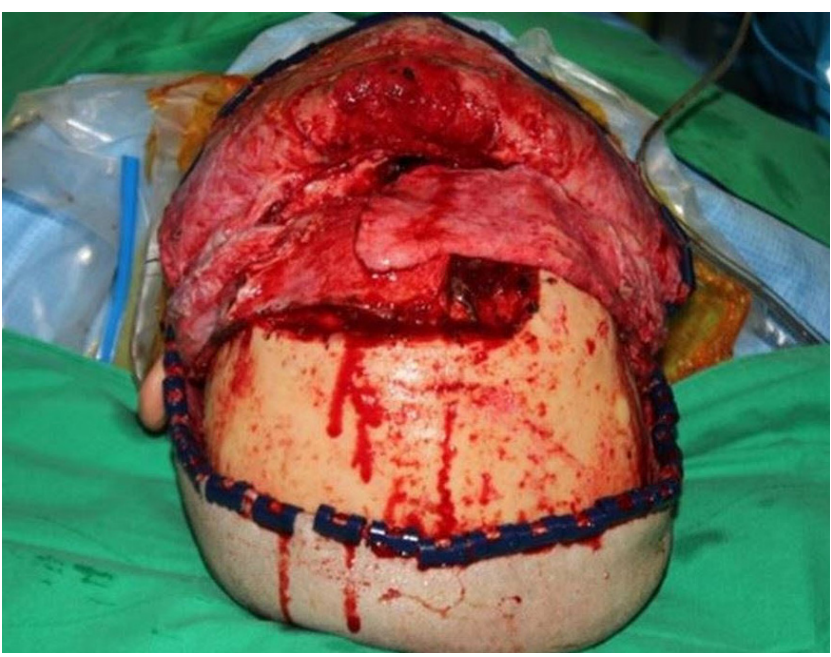

Fig. 4. Sufficient volume and length of the extended temporalis muscle flap was confirmed.

stead, in which the temporalis muscle flap was elevated with the deep temporal artery including the galeal flap beyond the temporalis muscle. When the flap was elevated, the deep temporal artery was preserved and circulation of the distal extended temporalis muscle flap was confirmed. When the flap was rotated to cover the defect on the frontal sinus and skull base, a sufficient volume was confirmed. Finally, the bilateral extended temporalis flap was overlapped to fill the nasocranial communication and inset (Figs. 3, 4).

\section{DISCUSSION}

Anterior skull base defects can cause major complications such 
as fatal infection following a nasocranial communication, cerebrospinal fluid leakage, tension pneumocephalus, seizure and meningocele [10-12]. Therefore, the ideal option for skull base reconstructions should include the following: watertight sealing to prevent cerebrospinal fluid leakage, complete separation of the nasocranial spaces, sufficient volume to fill the dead space and well circulated tissue to cover the defect [13-15].

In particular, free vascularized flaps are likely to be chosen for patients with prior free vascularized flaps are good candidates for patients with previous skull surgeries, radiation therapy or chemotherapy [16]. However, donor site morbidity and long operation time with microanastomoses are limitations, especially in patients with chronic diseases. Therefore, a local flap, such as a galeal flap or a temporalis muscle flap, would be first considered.

In the present case, the galea above the tumor was resected because of tumor invasion. Therefore, a galeal flap around the tumor could not be used to reconstruct the defect. Because the distance from the temporalis muscle to the center of the defect was longer than the temporalis muscle flap, a temporalis muscle flap was insufficient to cover the defect. Furthermore, because the superficial temporal artery and vein were already separated from the temporalis muscle after neurosurgery, a reverse temporalis muscle flap with or without galeal flap was unable to be used as well. In this situation, the extended temporalis flap could be an option. The extended temporalis flap differs from other options including the temporalis muscle flap and the reverse temporalis muscle flap with or without galeal flap which is based on superficial temporal artery because the extended temporalis flap is based on deep temporal vessels [17]. By simultaneously elevating the parietal galeal flap from the temporalis muscle flap, the length of flap can be extended, too. Because it did not contain the superficial temporal vessels, adequate circulation of the distal temporalis muscle should be confirmed when the flap is elevated. If circulation of temporalis muscle is confirmed first, because the galeal flap itself has good capillary circulation, the viability of galeal flap connected with temporalis muscle can be secured $[18,19]$. Nonetheless, operators must confirm the circulation of the galeal flap in direct, so we confirmed adequate circulation with blood permeation by putting the galeal flap on wet gauze for 2 to 3 minutes.

In conclusion, when a traditional galeal flap that receives blood flow from the supratrochlear artery or supraorbital artery and temporalis muscle flap with galeal flap based on superficial temporal artery cannot be used, the extended temporalis flap consisting of temporalis muscle flap and parietal galeal flap based on deep temporal artery can be considered an option for skull base reconstruction.

\section{NOTES}

\section{Conflict of interest}

No potential conflict of interest relevant to this article was reported.

\section{Ethical approval}

The study was approved by the Institutional Review Board of Severance Hospital (IRB No. 4-2019-0005) and performed in accordance with the principles of the Declaration of Helsinki. The informed consent was waived.

\section{Patient consent}

The patient provided written informed consent for the publication and the use of his images.

\section{ORCID}

Soon Won Chung https://orcid.org/0000-0002-4761-3942 Jong Won Hong https://orcid.org/0000-0002-7762-0940 Won Jai Lee https://orcid.org/0000-0003-3056-0503 Yong Oock Kim https://orcid.org/0000-0002-3756-4809

\section{REFERENCES}

1. Chang DW, Langstein HN, Gupta A, De Monte F, Do KA, Wang X, et al. Reconstructive management of cranial base defects after tumor ablation. Plast Reconstr Surg 2001;107:134655.

2. Jones NF, Schramm VL, Sekhar LN. Reconstruction of the cranial base following tumour resection. Br J Plast Surg 1987;40: 155-62.

3. Ketcham AS, Hoye RC, Van Buren JM, Johnson RH, Smith RR. Complications of intracranial facial resection for tumors of the paranasal sinuses. Am J Surg 1966;112:591-6.

4. Siniscalchi EN, Angileri FF, Mastellone P, Catalfamo L, Giusa $\mathrm{M}$, Conti A, et al. Anterior skull base reconstruction with a galeal-pericranial flap. J Craniofac Surg 2007;18:622-5.

5. Wilson JS, Westbury G. Combined craniofacial resection for tumour involving the orbital walls. Br J Plast Surg 1973;26:4456.

6. Valentini V, Fabiani F, Nicolai G, Torroni A, Gennaro P, Marianetti TM, et al. Use of microvascular free flaps in the reconstruction of the anterior and middle skull base. J Craniofac Surg 2006;17:790-6.

7. Menderes A, Yilmaz M, Vayvada H, Demirdover C, Barutcu A. Reverse temporalis muscle flap for the reconstruction of orbital exenteration defects. Ann Plast Surg 2002;48:521-6.

8. Kwon SG, Kim YO, Rah DK. Anterior cranial base reconstruc- 
tion with a reverse temporalis muscle flap and calvarial bone graft. Arch Plast Surg 2012;39:345-51.

9. Kim YO, Park BY. Reverse temporalis muscle flap: treatment of large anterior cranial base defect with direct intracranial-nasopharyngeal communication. Plast Reconstr Surg 1995;96:57684.

10. Boyle JO, Shah KC, Shah JP. Craniofacial resection for malignant neoplasms of the skull base: an overview. J Surg Oncol 1998;69:275-84.

11. Gagliardi F, Boari N, Mortini P. Reconstruction techniques in skull base surgery. J Craniofac Surg 2011;22:1015-20.

12. Schmalbach CE, Webb DE, Weitzel EK. Anterior skull base reconstruction: a review of current techniques. Curr Opin Otolaryngol Head Neck Surg 2010;18:238-43.

13. Gil Z, Abergel A, Leider-Trejo L, Khafif A, Margalit N, Amir A, et al. A comprehensive algorithm for anterior skull base reconstruction after oncological resections. Skull Base 2007;17:2537.

14. Girod A, Boissonnet H, Jouffroy T, Rodriguez J. Latissimus dorsi free flap reconstruction of anterior skull base defects. J Craniomaxillofac Surg 2012;40:177-9.

15. Hanasono MM, Silva A, Skoracki RJ, Gidley PW, DeMonte F, Hanna EY, et al. Skull base reconstruction: an updated approach. Plast Reconstr Surg 2011;128: 675-86.

16. Atabey A, Vayvada H, Menderes A, Kirisoglu U, Barutcu A. A combined reverse temporalis muscle flap and pericranial flap for reconstruction of an anterior cranial base defect: a case report. Ann Plast Surg 1997;39:190-2.

17. Pinto F, Magalhaes R, Durazzo M, Brandao L, Rodrigues AJ Jr. Galeal flap based on superficial temporal vessels for oral cavity and pharynx reconstruction: an anatomical study. Clinics (Sao Paulo) 2008;63:97-102.

18. Potparic Z, Fukuta K, Colen LB, Jackson IT, Carraway JH. Galeo-pericranial flaps in the forehead: a study of blood supply and volumes. Br J Plast Surg 1996;49:519-28.

19. Batchelor J, McGuinness A. Microvascular anatomy of the galeal and temporoparietal fascia. Plast Reconstr Surg 1996;97: 1085. 